\author{
복합재료를 적용한 항공기용 카메라 구조 \\ 경량화 설계 및 최적조건 선정에 관한 연구 \\ 김병준 ${ }^{*}$ 이준호 ${ }^{* *}$, 이행복 ${ }^{* * *}$, 정대윤 ${ }^{* * *}$, 전성식 ${ }^{*+}$
}

\title{
A Study on the Vibration Analysis and Optimization for the Composite Optical Structure of an Aircraft
}

\author{
Byeong-Jun Kim*, Jun-Ho Lee ${ }^{* *}$, Haeng-Bok Lee ${ }^{* * *}$, Dae-Yoon Jung ${ }^{* * *}$, and Seong-Sik Cheon ${ }^{*+}$
}

\begin{abstract}
This paper presents the vibration characteristics and the optimization using the orthogonal array about applied composite optical structure of an aircraft. To acquire the vibration characteristics for stable line of sight, modal analysis are performed by using multi-body program ADAMS. And to optimize optical structure, for design variables were selected, larger-the-better characteristics were considered using results of $\mathrm{S} / \mathrm{N}$ ratio and orthogonal array $\mathrm{L}_{9}\left(3^{4}\right)$. When bearing constraints are selected, radial, axial and moment stiffness value are used to analysis for optimization until now. But B.S.R which is non-dimensional parameter is proposed, structures including bearings can be used for optimization. And then having a result of lager-the-better, the optimized values of each design variable were successfully suggested.

\section{초 록}

본 연구에서는 항공기용 카메라구조의 진동특성 파악하고 최적조건을 선정하여 구조의 경량화 설계 방안을 제시하였다. 다 물체 동력학 프로그램인 $\mathrm{ADAMS}$ 를 이용하여 모드해석을 진행하고, 해석 결과를 가지고 직교법을 이용하여 항공기용 카메라 구조의 경량화 및 최적조건을 선정하여 이전의 항공기용 카메라 구조와 모드해석 결과를 서로 비교하였다. 또한, 기존에 제시 되어진 베어링의 차원의 값을 무차원의 값으로 전환하여 보다 효과적인 베어링의 기준을 선정하였으며, 비교된 결과를 토대 로 최적화된 항공기용 카메라 구조가 제안되었다.
\end{abstract}

Key Words : 광학구조(optical Structure), 고유진동수(natural frequency), 최적화(optimization), 베어링 강성비(B.S.R), SN비(SN Ratio)

\section{1. 서 론}

항공기에 카메라를 장착하여 상공에서 지상을 관측함으로 써 보다 광범위한 부분을 관측할 수 있고, 첨단의 카메라가
장착되어 보다 세밀하고 정확하게 관측할 수 있게 되었다. 하지만 항공기 카메라 관측 시에는 다양한 형태의 진동환경 에 노출이 될 수 있으므로 진동환경 속에서도 정확한 이미지 획득과 제공된 이미지를 관측자에게 가시화를 하기 위한 안

2012년 12월 05일, 수정: 2012년 12월 21일, 게재승인: 2012년 12월 24일

*+ 국립 공주대학교 공과대학 기계자동차공학부, Corresponding author(E-mail:sscheon@kongju.ac.kr)

* 국립 공주대학교 공과대학 기계공학과 대학원

** 국립 공주대학교 광공학과

*** 국방과학 연구소 
정화된 설계가 필요하다.

안정화 설계를 위해 진동 특성에 우수하며 밀도가 낮고 높은 강성을 가진 복합소재를 적용하여 진동 환경에 대한 안 정화된 설계를 도출해내면서 동시에 항공기용 카메라 구조의 경량화 설계 기법을 제시 할 수 있다[1].

특히 탄소섬유 강화 복합소재 및 마그네슘합금의 경우 진 동감쇠 특성이 우수하기 때문에, 본 항공기용 카메라 구조의 경량화 설계 및 최적조건 선정에 관한 연구를 포함한 경량화 및 진동 환경에 우수한 강인구조 설계 연구에 많이 적용 되 어 지고 있다. Fujita는 헬리콥터용 비디오카메라에 대한 진 동해석을 수행하였고, Taha는 무인헬기의 시선획득 향상에 대한 연구를 진행하였으며, Mondragon은 무인헬리콥터의 진 동해석에 관해 연구하였다[1-4].

본 연구에서는 항공기용 카메라 구조의 진동해석 결과를 바탕으로 구조물의 진동에 대한 강인 구조 설계기법을 도출 해 내기 위해 구조물의 적합한 두께와 베어링의 조건을 변수 로 선정하였다. 변수로 선정된 베어링의 조건을 차원의 값으 로 정의되어진 기존의 제시 방법과는 다르게 진동감쇠성에 우수한 베어링의 지표를 나타내고자 무차원의 값으로 단순화 하여 제시하였다. 제시되어진 결과는 기존의 차원의 값을 적 용한 경우보다 베어링에 관하여 효과적으로 비교 분석하는데 쓰여 질 수 있다.

항공기용 카메라구조 진동해석을 위해 동력학 프로그램인 $\mathrm{ADAMS}$ 를 사용하였고, 직교법을 이용하여 선정된 조건변수 들의 최적화 수행이 진행되어졌다.

\section{ADAMS 모델링 및 적용 재료 특성}

\subsection{ADAMS 모델 형상 및 진동 배경 이론}

항공기용 카메라는 아래 그림과 같이 하우징과, 내부짐발 및 프레임으로 크게 구분 되어 질 수 있다.

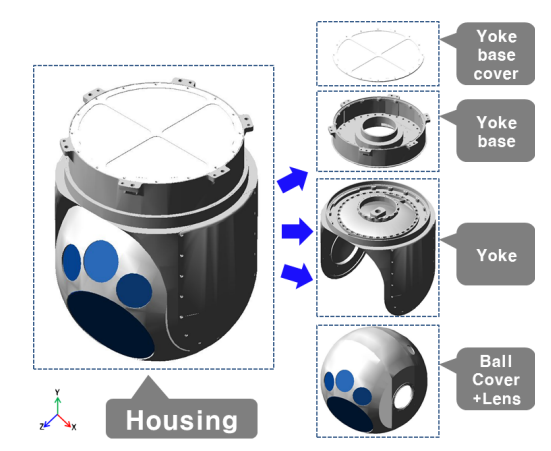

Fig. 1 Housing.

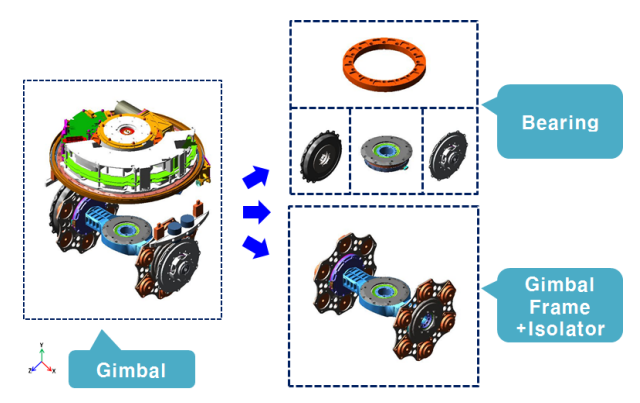

Fig. 2 Inside gimbal and frame.

Table 1 Bearing stiffness and isolator dynamic spring constant

\begin{tabular}{|c|c|c|c|c|}
\hline \multicolumn{3}{|l|}{ Type } & \multicolumn{2}{|c|}{ Value } \\
\hline \multirow{9}{*}{$\begin{array}{l}\text { Bearing stiffness } \\
{[\mathrm{MN} / \mathrm{m}]}\end{array}$} & \multicolumn{2}{|c|}{$\mathrm{CAZ}$} & Radial & 724 \\
\hline & \multirow{4}{*}{ CEL } & \multirow[b]{2}{*}{ Left } & & \\
\hline & & & Radial & 254 \\
\hline & & \multirow[b]{2}{*}{ Right } & $\begin{array}{l}\text { Axidi } \\
\text { Radial }\end{array}$ & 146 \\
\hline & & & Axial & 124 \\
\hline & \multirow{2}{*}{\multicolumn{2}{|c|}{ FAZ }} & Radial & 210 \\
\hline & & & Axial & 75.9 \\
\hline & \multirow{2}{*}{\multicolumn{2}{|c|}{ FEL }} & Radial & 198 \\
\hline & & & Axial & 79.7 \\
\hline \multirow{2}{*}{$\begin{array}{l}\text { Isolator spring constant } \\
{[\mathrm{kN} / \mathrm{m}]}\end{array}$} & \multirow{2}{*}{\multicolumn{2}{|c|}{ AM006-9 }} & Radial & 127 \\
\hline & & & Axial & 140 \\
\hline
\end{tabular}

세부 과정으로는, 단품간의 어셈블리 적용은 파트의 병합 및 고정 조인트를 사용하고, 단품과 방진구 및 베어링의 어 셈블리는 부싱 조인트를 사용하여 모델링을 진행하였다. 본 연구의 목적인 진동해석에서 응답을 결정하는 베어링과 방진 구에 사용된 강성값과 스프링 상수 값은 Table 1같이 정의 되어 있다. 동일한 X축의 기준을 가지고 12 개의 Lord사의 방진구가 설계되었으며[5], 베어링의 경우에는 Kaydon사의 베어링이 장착되었다[6]. 베어링의 장착 위치 및 형상에는 $\mathrm{Y}$ 축을 중심으로 요크베이스 (yoke base)에 1개, $\mathrm{X}$ 축 기준으로 요크 기어(yoke gear)에 2개, 짐발 프레임 (gimbal frame)과 카메라 장착 부분에 2 개, 총 5 개의 베어링이 장착 되어있는 것이 확인되었다.

진동 구조 응답해석의 경우에는 베어링의 강성 및 방진구 의 스프링강성이 가장 큰 역할을 담당하는데[1], 보다 정확한 진동해석을 위하여 베어링의 축 방향(Axial) 및 반경방향 (Radial)의 강성값에 추가적으로 비틀림 강성값을 고려하여 해 석의 신뢰를 높일 필요가 있다. 비틀림 강성은 한축을 기준으 로 회전하는 기계시스템의 힘 중 가장 핵심이 되는 힘이라고 정의된다[7]. 따라서 베어링이 장착되는 부품과 부품 사이에는 회전력이 작용하여 모멘트가 발생하기 때문에 발생된 모멘트 값을 견딜 수 있는 베어링의 비틀림 강성을 계산하고 계산되 어진 강성값을 $\mathrm{ADAMS}$ 에 적용한 후 해석을 진행하였다[8]. 


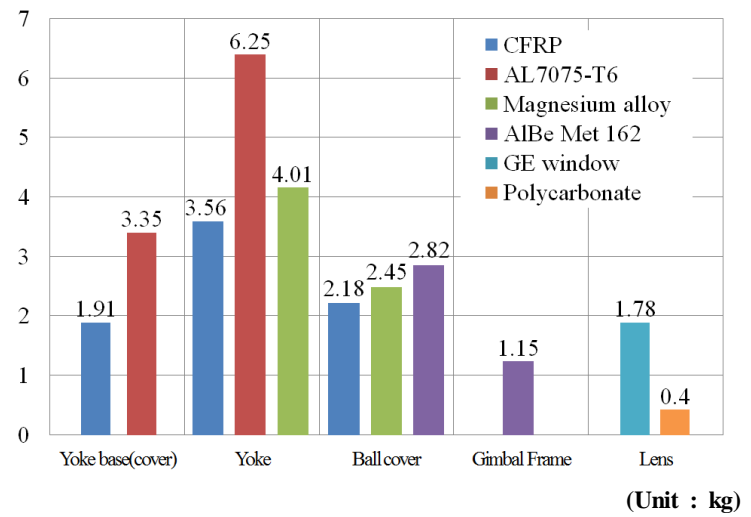

Fig 3 Result of material properties to apply to part body.

$$
K=\frac{M}{\theta}
$$

여기서 $\mathrm{K}$ 는 비틀림 강성, $\mathrm{M}$ 은 모멘트, $\theta$ 는 베어링의 볼 사이의 간격이다. 식 (1)을 이용하여 베어링의 최대/최소 비 틀림 강성을 구하면 다음과 같다.

Table 2 Bearing moment stiffness value

\begin{tabular}{c|cc}
\hline \hline & Min. moment stiffness & Max. moment stiffness \\
\hline Value & $624 \mathrm{~N} \cdot \mathrm{m} / \mathrm{rad}$ & $812,280 \mathrm{~N} \cdot \mathrm{m} / \mathrm{rad}$ \\
\hline \hline
\end{tabular}

비틀림 강성의 최대/최소값을 가지고 진동해석을 수행하 여, 본 연구의 진동환경에 의한 안정화된 목표 고유진동수 값인 $75 \mathrm{~Hz}$ 값에 상응하는 베어링의 비틀림 강성을 선정하였 다. 그러나 베어링의 비틀림 강성값은 볼의 개수 및 볼과 베 어링 사이의 유압에 따라 변화 시킬 수 있는 값이다[8]. 그 렇기 때문에 강인구조에 최적화를 설계기법의 정의를 내리기 위해 베어링에 비틀림 강성에 관계없이 최적화된 설계변수의 제안이 필요하다고 판단되어진다. 그에 따른 비틀림 강성값 을 잡음인자로 선정하고, 몬테카를로 기법[9]에 의해 최대/최 소값의 비틀림 강성값 중 무작위로 선정된 비틀림 강성값을 이용한 구조 최적화가 진행되었다.

\section{2 적용 재질 특성 및 진동 구조 해석 방법}

항공기용 카메라 구조의 모드해석에 사용된 탄소섬유 에 폭시 복합재료[1], AL7075-T6, 마그네슘 합금, 알루미늄-베릴 륨 Met 162 , 게르마늄 window, 폴리카보네이트의 물성값을 Table 3에서 보여주고 있다.

항공기용 카메라 구조에 적용된 결과를 Fig. 3과 같이 나 타내었다. 요크베이스, 요크, 볼 커버, 짐발 및 렌즈에 적용 한 결과값을 가지고, 그 중에서 복합재료를 적용한 경우와 복합재료를 적용하지 않는 경우를 Table 4에 나타내었다.
Table 3 Material properties

\begin{tabular}{c|ccc}
\hline \hline Material & $\begin{array}{c}\text { Young's modulus } \\
{[\mathrm{GPa}]}\end{array}$ & $\begin{array}{c}\text { Poisson's } \\
\text { ratio }\end{array}$ & $\begin{array}{c}\text { Density } \\
{\left[\mathrm{kg} / \mathrm{m}^{3}\right]}\end{array}$ \\
\hline CFRP & 120.0 & 0.3 & 1,600 \\
AL7075-T6 & 71.7 & 0.33 & 2,810 \\
Mg alloy & 45.0 & 0.35 & 1,800 \\
AlBe Met 162 & 193.0 & 0.17 & 2,070 \\
Ge window & 103.0 & 0.28 & 5,330 \\
Polycarbonate & 25.0 & 0.40 & 1,200 \\
\hline \hline
\end{tabular}

Table 4 Total housing mass and inside gimbal average mass

\begin{tabular}{c|cc}
\hline \hline Part body & Material & Housing \\
\hline Yoke base & CFRP & \\
Yoke & CFRP & \\
Ball cover & CFRP & $9.2 \mathrm{~kg}$ \\
Lens & Polycarbonate & \\
Gimbal Frame & AlBe Met 162 & \\
\hline Yoke base & AL7075-T6 & \\
Yoke & AL7075-T6 & $15.35 \mathrm{~kg}$ \\
Ball cover & Albe Met 162 \\
Lens & GE window & \\
Gimbal Frame & Albe Met 162 \\
\hline \hline
\end{tabular}

복합재료를 적용한 구조의 질량은 $9.2 \mathrm{~kg}$ 이며, 복합재료를 적용하지 않은 구조는 $15.35 \mathrm{~kg}$ 임이 밝혀졌다. 항공기용 카 메라 구조의 목표 질량은 $25 \mathrm{~kg}$ 이므로 두가지 경우에 따라 다른 질량을 내부짐발에 적용하여 해석을 진행되면, 결과값 에 대한 신뢰성이 떨어진다고 판단되어진다. 따라서 복합소 재를 적용한 경우와 적용하지 않은 경우의 질량을 목표 질량 에서 제외한 나머지 질량의 평균값인 $12.83 \mathrm{~kg}$ 을 적용한 해 석이 진행되었다.

\section{3. 직교법을 이용한 최적설계 조건선정}

\section{1 직교배열표}

$3 \mathrm{n}$ 요인계획법이란 $\mathrm{n}$ 개의 인자에 대해 각각의 인자의 수준을 3 가지로 $(1,2,3)$ 나타내고, 실험(해석)을 수행하여 각 인자의 유의성을 판정하는 방식을 말한다.

Table $5 \quad \mathbf{L}^{9}\left(3^{4}\right)$ orthogonal array

\begin{tabular}{c|cccc}
\hline \hline & A & B & C & D \\
\hline 1 & 1 & 1 & 1 & 1 \\
2 & 1 & 2 & 2 & 2 \\
3 & 1 & 3 & 3 & 3 \\
4 & 2 & 1 & 2 & 3 \\
5 & 2 & 2 & 3 & 1 \\
6 & 2 & 3 & 1 & 2 \\
7 & 3 & 1 & 3 & 2 \\
8 & 3 & 2 & 1 & 3 \\
9 & 3 & 3 & 2 & 1 \\
\hline \hline
\end{tabular}


4가지 인자의 모든 효과를 구하려면 해석의 횟수를 $3{ }^{4}=81$ 회로 하여 인자들의 주효과와 교호작용을 구해야 하지만, 교 호작용의 경우 무시할 수 있는 경우의 수가 많으며 이러한 경우에 사용되는 것이 일부실시법이다. 일부 실시법은 무시 할 수 있는 효과를 배제하고 해석함으로서 같은 인자수의 요 인계획법에 비해 실험의 횟수를 줄 일수 있다. 직교배열법은 일부 실시법의 한 종류로서 $\mathrm{L}^{9}\left(3^{4}\right)$ 는 3 수준계의 직교표의 하 나로 Table 5 와 같이 배열 할 수 있으며, $\mathrm{L}^{9}\left(3^{4}\right)$ 의 경우 만약 교호작용과 오차가 무시된다면 9 회의 해석에서 4 인자까지 배 치가 가능하다[10]. 4인자 요소를 선택할 때 해설 결과에 주 요한 영향을 끼치는 요소를 예상하여 선택하였으며 각각의 요소 인자를 Table 6에 나타내었다.

Table $6 \quad L^{9}\left(3^{4}\right)$ design variables and levels

\begin{tabular}{l|ccc}
\hline D.V. & 1 & 2 & 3 \\
\hline A[Yoke base] & $5 \mathrm{~mm}$ & $4 \mathrm{~mm}$ & $3.5 \mathrm{~mm}$ \\
B[Ball cover front \& rear] & $3 \mathrm{~mm}$ & $2.5 \mathrm{~mm}$ & $2 \mathrm{~mm}$ \\
C[Ball cover middle] & $2 \mathrm{~mm}$ & $1.8 \mathrm{~mm}$ & $1.5 \mathrm{~mm}$ \\
D[B.S.R] & 1.18 & 2.55 & 14.5 \\
\hline \hline
\end{tabular}

베어링을 선정할 때 가장 중요한 요소인 강성값이 무차원 의 값으로 변환된 강성비가 설계변수로 선정 되었으며, 다음 과 같이 베어링 강성비(B.S.R, bearing stiffness ratio)를 정의 되어있다.

$$
\text { B.S.R }=\frac{\text { Radial stiffness }}{\text { Axialstiffness }}
$$

무차원으로 제시된 B.S.R은 진동 감쇠에 우수한 베어링을 선정하는데 보다 효과적인 지표로 사용되어 질 수 있으며, 본 연구에는 Table 8 및 식 (2)의 조건에 맞추어 계산된 설 계변수를 적용한 최적화가 진행되었다.

\subsection{SN비(Signal to noise ratio)}

$\mathrm{SN}$ 비를 최대로 함으로써 목표치를 유지하며 변동에 대한 산포를 줄여주기 때문에 잡음에 대하여 둔감하게 된다. 그러 므로 최적설계에서 목표치에 대한 최적조합이 구해지며 강도 및 수명, 연료효율 등과 같이 클수록 좋은 망대특성이 본 해 석에 적용 되었다[11].

$$
S N \text { 비 }=-10 \log \left[\frac{1}{n} \sum_{i=1}^{n} \frac{1}{t_{i}^{2}}\right]
$$

여기서 ti는 무작위로 선정된 비틀림 강성값을 가지고 얻어진 고유진동수 값이며, $\mathrm{n}$ 은 선정된 개수이다.

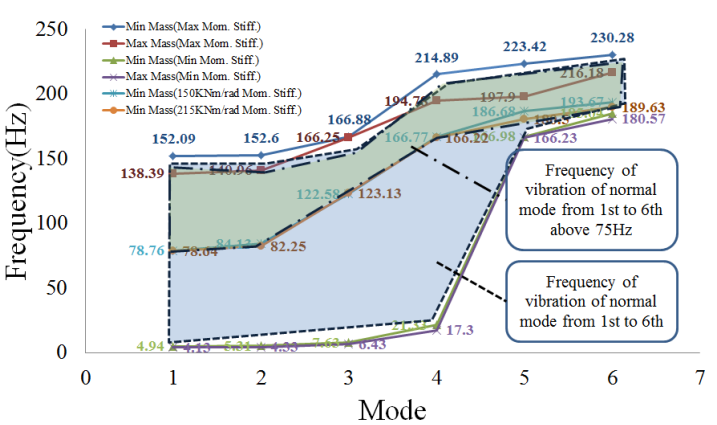

Fig 4 Result of modal analysis.

\section{4. 모드해석 및 최적설계 결과}

\section{1 모드해석}

모드 해석에서는 해석하려는 모델의 자유도 수만큼의 모 드가 존재하며, 이러한 모드를 전부 계산해내기는 불가능하 다. 또한 모델의 종류, 형상, 특성 등에 따라서 고차 모드에 서는 실제 실험값과 오차가 커지게 된다. 따라서 저차의 몇 개 모드만으로도 충분히 정확한 결과 값을 얻을 수 있으며 [12], 다음과 같이 복합재료를 적용한 모델과 적용하지 않은 모델의 결과값을 비교하여 나타내었다.

Table 7 Mode shape from 1st to 6th mode

\begin{tabular}{c|cc|cc}
\hline \hline \multirow{3}{*}{ Mode } & \multicolumn{2}{|c|}{ Applied composite } & \multicolumn{2}{c}{ Not applied composite } \\
\cline { 2 - 5 } & Min. mom. & Max. mom. & Min. mom. & Max. mom. \\
& stiffness & stiffness & stiffness & stiffness \\
\hline \multirow{2}{*}{ 1st } & Z axis & X axis & Z axis & Z axis \\
& Yoke rot. & Yoke rot. & Yoke rot. & Yoke rot. \\
2nd & X axis & Z axis & X axis & X axis \\
& Yoke rot. & Yoke rot. & Yoke rot. & Yoke rot. \\
3rd & Y axis & Y axis & Y axis & Y axis \\
& Yoke rot. & Gim. trans. & Yoke rot. & Gim. trans. \\
4th & X axis & Z axis & X axis & X axis \\
& B. cov. rot. & Gim. rot & B. cov. rot. & Gim. rot \\
5th & Y axis & Y axis & Y axis & $Z$ axis \\
& Gim. trans. & Gim. rot. & Gim. trans. & Gim. rot. \\
6th & $Z$ axis & Reverse & Z axis & Y axis \\
& Gim. trans. & of 5th & Gim. trans. & Gim. rot. \\
\hline \hline
\end{tabular}

본 연구에서 모드해석은 18 개의 자유도를 가진 결과를 얻 었으며, 오차범위가 크지 않는 범위내의 저차모드 6 개의 모드 까지 고유진동수와 모드형상을 $\mathrm{ADAMS}$ 소프트웨어에서 확인 할 수 있었다. 비틀림 강성의 최대/최소값이 적용되어진 구조 에 복합재료를 적용한 구조의 첫 번째 모드값은 $4.9 \sim 152 \mathrm{~Hz}$ 값이 나타났고 복합재료를 적용하지 않은 구조는 $4.1 \sim 138 \mathrm{~Hz}$ 값이 나타났다. 첫 번째 모드를 기준으로 볼 때 복합재료를 적용한 구조가 적용하지 않은 구조의 모드 해석 값이 $12 \%$ 향상됨을 보여주고 있으며, 질량도 $6.2 \mathrm{~kg}$ 의 감소 효과를 가 져왔다. 또한 진동환경에 안정화된 목표 고유진동수 이상의 
진동 특성을 갖기 위한 베어링의 비틀림 강성값은 복합재료를 적용한 구조에는 $150 \mathrm{kN} \cdot \mathrm{m} / \mathrm{rad}$ 으로 나타났고, 복합재료를 적용 하지 않은 구조에는 $215 \mathrm{kN} \cdot \mathrm{m} / \mathrm{rad}$ 으로 나타났다.

Table 7에서 볼 수 있듯이, 복합재료를 적용한 구조-최소 비틀림 강성과 복합재료를 적용하지 않은 구조-최소 비틀림 강성의 $1,2,3$ 차 모드는 각각 $\mathrm{Z}, \mathrm{X}, \mathrm{Y}$ 축 요크의 회전 모드 형상을 보였다. 다음 $4,5,6$ 차 모드는 $\mathrm{X}, \mathrm{Y}, \mathrm{Z}$ 축 볼 커버 및 짐발 프레임의 회전 및 왕복운동의 모드형상을 보였다. 복합재료를 적용한 구조-최대 비틀림 강성과 복합재료를 적 용하지 않은 구조- 최대 비틀림 강성의 1 차부터 6 차 모드까 지는 $\mathrm{X}, \mathrm{Y}, \mathrm{Z}$ 축을 기준으로 요크와 짐발 프레임의 회전과 왕복운동의 조합을 가진 모드형상을 확인 할 수 있었다. 3 차 모드의 경우에만 모드형상이 같음을 확인 하였다.

\section{2 최적설계}

$\mathrm{SN}$ 비의 1 번 해석결과부터 9 번 해석 결과 까지 $\mathrm{SN}$ 비 값을 Table 8에서 나온 인자와 수준 별로 평균을 내서 그래프로 나타내면 다음과 같다.

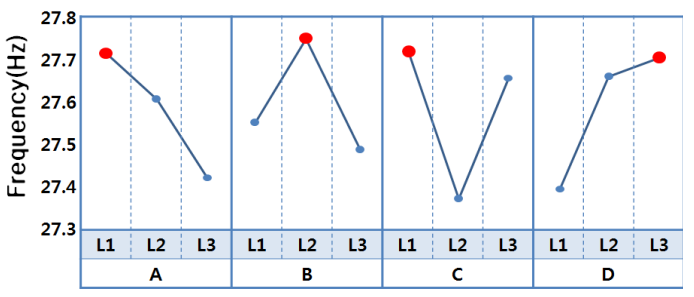

Fig 5 Average of SN \& best picks.

$\mathrm{SN}$ 비를 통하여 $\mathrm{A}$ 인자, $\mathrm{B}$ 인자, $\mathrm{C}$ 인자, $\mathrm{D}$ 인자의 각각의 수 준의 평균값을 Fig. 5에 나타내어 최대 망대특성 값을 선정 하였다.

망대특성의 결과를 근거로 하였을 때, $\mathrm{A}$ 인자인 요크베이 스와 $\mathrm{C}$ 인자인 중간 볼 커버를 제외한 B인자(Front \& rear ball cover)의 2수준, $\mathrm{D}$ 인자(B.S.R : 14.5)는 3수준 일 때 최 적화에 가까운 것으로 사료된다.

최적화 된 조건을 적용하여 이전 모델과 결과값을 Table 9와 같이 비교하여 나타내었다.

두께 변형 및 B.S.R의 망대특성에 의한 최적화를 통해 이 전 복합재료를 적용한 구조에 비해 $13.5 \%$ 의 경량화의 결과 가 보여 지고 있다. Table 9에서와 같이 볼 커버의 경량화를 제시함과 동시에 기존의 모델의 진동특성을 유지하는 효과적 인 설계 제안이 이루어졌다.

Table 9 Result of applied optimization factor

\begin{tabular}{c|cccc}
\hline \hline \multirow{2}{*}{ Mode } & \multicolumn{2}{|c}{ Optical structure } & \multicolumn{2}{c}{ Mass, ball cover (FR, RR) } \\
\cline { 2 - 5 } & Before opt. & After opt. & Before opt. & After opt. \\
\hline 1st & $152.09 \mathrm{~Hz}$ & $152.42 \mathrm{~Hz}$ & & \\
2nd & $152.60 \mathrm{~Hz}$ & $152.84 \mathrm{~Hz}$ & & \\
3rd & $166.88 \mathrm{~Hz}$ & $167.17 \mathrm{~Hz}$ & \multirow{2}{*}{$1.33 \mathrm{~kg}$} & $1.15 \mathrm{~kg}$ \\
4th & $214.89 \mathrm{~Hz}$ & $216.16 \mathrm{~Hz}$ & & \\
5th & $223.42 \mathrm{~Hz}$ & $224.63 \mathrm{~Hz}$ & & \\
6th & $230.28 \mathrm{~Hz}$ & $231.48 \mathrm{~Hz}$ & & \\
\hline \hline
\end{tabular}

\section{5. 결 론}

본 연구에서는 항공기용 카메라 구조 경량화 재질의 선정 및 신뢰도 파악과, 베어링 및 두께 선정을 통하여 구조물의 최적 설계 방안을 모색하였다.

항공기용 카메라 구조에 복합재료를 적용한 경우, 적용하 지 않은 구조의 무게를 $15.35 \mathrm{~kg}$ 에서 $9.2 \mathrm{~kg}$ 으로 경량화 시 켰으며, 경량화 동시에 고유진동수 값도 1차 모드에서 6차 모드까지 최대 $25 \mathrm{~Hz}$ 까지 향상된 결과를 얻을 수 있었다. 또한, 진동환경에 안정된 고유진동수를 갖는 베어링의 비틀 림 강성값이 복합재료를 적용한 구조에는 $150 \mathrm{kN} \cdot \mathrm{m} / \mathrm{rad}$ 으로

Table 8 Result of parameter diagram

\begin{tabular}{c|ccccccccccc}
\hline \hline & $\mathrm{T} 1$ & $\mathrm{~T} 2$ & $\mathrm{~T} 3$ & $\mathrm{~T} 4$ & $\mathrm{~T} 5$ & $\mathrm{~T} 6$ & $\mathrm{~T} 7$ & $\mathrm{~T} 8$ & $\mathrm{~T} 9$ & T10 & SN ratio \\
\hline Mom. stiff. [kN $\cdot \mathrm{m} / \mathrm{rad}]$ & 31.12 & 24.08 & 3.35 & 6.72 & 514.11 & 668.04 & 77.08 & 276.70 & 80.97 & 98.47 & \\
1st nat. freq.[Hz] & 31.80 & 27.99 & 10.46 & 14.81 & 121.45 & 134.61 & 49.82 & 92.25 & 51.04 & 56.18 & 27.61 \\
2nd nat. freq.[Hz] & 32.13 & 28.28 & 10.56 & 14.96 & 123.07 & 136.38 & 50.35 & 93.39 & 51.59 & 56.79 & 27.70 \\
3rd nat. freq.[Hz] & 32.47 & 28.58 & 10.67 & 15.12 & 124.34 & 137.64 & 50.90 & 94.42 & 52.14 & 57.41 & 27.79 \\
4th nat. freq.[Hz] & 31.36 & 27.62 & 10.33 & 14.62 & 117.16 & 129.24 & 49.02 & 89.90 & 50.21 & 55.22 & 27.50 \\
5th nat. freq.[Hz] & 31.84 & 28.03 & 10.48 & 14.84 & 119.70 & 131.75 & 49.83 & 91.76 & 51.05 & 56.17 & 27.63 \\
6th nat. freq.[Hz] & 32.07 & 28.23 & 10.54 & 14.94 & 122.01 & 134.92 & 50.24 & 92.93 & 51.47 & 56.66 & 27.68 \\
7th nat. freq.[Hz] & 31.55 & 27.77 & 10.37 & 14.70 & 120.49 & 133.49 & 49.44 & 91.56 & 50.65 & 55.75 & 27.54 \\
8th nat. freq.[Hz] & 32.56 & 28.68 & 10.73 & 15.19 & 120.69 & 132.64 & 50.87 & 93.04 & 52.11 & 57.30 & 27.83 \\
9th nat. freq.[Hz] & 29.31 & 25.80 & 9.64 & 13.65 & 112.93 & 125.88 & 45.94 & 85.29 & 47.06 & 51.82 & 26.90 \\
\hline \hline
\end{tabular}


나타났고, 복합재료를 적용하지 않은 구조에는 $215 \mathrm{kN} \cdot \mathrm{m} / \mathrm{rad}$ 으로 나타났다. SN비를 통하여 최적 베어링의 B.S.R 값은 14.5 로 확인 되었으며 전후면의 볼 커버 최적 두께는 $3 \mathrm{~mm}$ 에서 $2.5 \mathrm{~mm}$ 로 줄일 수 있음이 확인되었다. 최적화된 결과를 바탕으로 이전 모델과 고유진동수를 비교한 결과 고유진동수 값을 유지 하면서 볼 커버의 무게도 $13.5 \%$ 의 감소 된 결과 를 보여주는 것으로 볼 때, 기존의 진동특성을 유지하면서 동시에 경량화가 이루어짐이 확인 되었다.

따라서 본 연구에서는 항공기용 카메라의 진동특성에 가 장 큰 영향을 끼치는 것은 재질과 베어링의 강성비 및 비틀 림 강성임이 밝혀졌고, 그 결과를 바탕으로 진동환경에 안정 화된 항공기용 카메라 구조를 제작할 수 있는 방안이 제시되 었다. 또한, 무차원의 베어링의 값을 나타내어 진동 감쇠성에 우수한 베어링 선정할 수 있는 기술적 기반을 정의하였다.

\section{후 기}

본 연구는 국방과학연구소가 지원하는 연구과제로 수행된 것이며, 지원에 대해 진심으로 감사드립니다(UD110080FD).

\section{참고문헌}

1) Kim, D.Y., Kwak, J.H., Lee, J.H., Park, K.W., Jeong, K.Y., and Cheon, S.S., "A Study on the Vibration Analysis for the Composite Multi-axial Optical Structure of an Aircraft," Journal of the Korean Society for Composite Materials, Vol. 24, No. 2, 2011, pp. 14-21.

2) Fujita, I., and Kunita, Y., "Application of aerial LSPIV to the 2002 flood of the Yodo River using a helicopter mounted high density video camera," Journal of Hydroenvironment Research, Vol. 5, No. 4, 2011, pp. 323-331.
3) Taha, Z., Tang, Y.R., and Yap, K.C., "Development of an onboard system for flight data collection of a small-scale UAV helicopter," Journal of Mechatronics, Vol. 21, No. 1, 2011, pp. 132-144.

4) Mondaragon, I.F., Campoy, P., Martinez, C., and Olivares, M., "Omnidirectional vision applied to Unmanned Aerial Vehicles (UAVs) attitude and heading estimation," Journal of Robotics and Autonomous System, Vol. 58, No. 6, 2010, pp. 809-819.

5) Kaydon., REALI-DLIM ${ }^{\circledR}$ Catalog 300 Ball \& Roller Bearings, Kaydon Co. 1td, Michigan USA, 2007.

6) Lord, Vibration, Shock \& Motion Control Products, Lord Co. 1td, USA, 2011.

7) http://www.wisegeek.com, Category : Industry, Subject : What is Torsional stiffness?, wiseGEEK Con. Cor., 2003-2012.

8) Nystrom, G., and Hoffman, T., SMA azimuth bearing, Technical Memorandum, SMA Technical report 114 Harvard University, 1997.

9) Rivera, A., Crepillo, M.L., Olivares, J., and Garcia, G., AgulloLopez F., "Effect of defect accumulation on ion-beam damage morphology by electronic excitation in lithium niobate : A MonteCarlo approach," Journal of Nuclear Instruments and Methods in Physics Research B, Vol. 268, 2010, pp. 2249-2256.

10) Lee, Y.M., Hang, S.H., and Kwon, O.J., "Prediction of chip breakability by an orthogonal array method," Proceeding of spring conference Korean Society for Precision Engineering 2001.

11) Park, S.H., Design of experiments, Minyoungsa Co., Seoul, 2005.

12) Cho, H.K., and Rhee, J., "Vibration in a satellite structure with a laminate composite hybrid sandwich panel," Composite Structures, Vol. 93, No. 10, 2011, pp. 2566-2574. 